\title{
A geografia social do zika no Brasil
}

\author{
JEFFREY LESSER I e URIEL KITRON ${ }^{I I}$
}

$\mathrm{H}$ Á UM DITADO que diz: “Mosquitos são democráticos; eles picam tanto os ricos como os pobres". Embora os insetos possam não ter uma consciência de classe muito desenvolvida, o fato é que a atual crise do vírus do zika teve impactos bem diferentes em cada classe, grupo social ou gênero - como, aliás, já ocorrera com epidemias anteriores de doenças transmitidas por mosquitos, da febre amarela à malária e à dengue. Em outras palavras, o zika é mais um indicador da desigualdade que persiste no Brasil contemporâneo, mesmo após várias décadas de democracia.

Doenças transmitidas por mosquitos afetam desproporcionalmente a maioria menos privilegiada da população brasileira, de várias maneiras. A crise atual é indicativa de disparidade existente não só em termos de classe, mas de uma variedade de outras questões ligadas à estrutura de classes. $\mathrm{O}$ vírus do zika teve impacto maior no Nordeste, nos estados de Bahia, Pernambuco e Rio Grande do Norte, onde uma percentagem maior da população é pobre e as condições climáticas são mais favoráveis à propagação de vírus transmitidos por mosquitos do que no Sul, mais rico e menos tropical. O impacto de questões éticas relacionadas ao vírus do zika também foi diferenciado: afinal, quem só tem condições de se tratar no Sistema Único de Saúde (SUS) depara com escolhas reprodutivas muito diferentes das de quem usa o sistema privado de saúde. Em alguns casos extremos, mulheres ricas simplesmente deixam o Brasil durante a gravidez, visto que o aborto no país só é legal se a gravidez colocar em risco a vida da mãe ou for resultado de estupro. Como acontece com todas as questões ligadas à reprodução humana, o gênero tem papel importante em termos de impactos e responsabilidades, e o discurso atual em torno do zika no Brasil é primordialmente dirigido às mulheres. Por exemplo, as autoridades de saúde têm recomendado que mulheres em áreas de risco evitem engravidar e até evitem ter relações sexuais, mas basicamente ignoram o papel dos homens na transmissão. O susto provocado pelo zika também levantou questões éticas no âmbito da ciência, por exemplo, o uso apropriado de produtos químicos para pulverização dentro das casas e os possíveis perigos de desenvolver mosquitos geneticamente modificados com vistas a interromper a transmissão do vírus.

As disparidades éticas e de classe relacionadas a questões de saúde em geral e a doenças transmitidas por mosquitos em especial não são nem novas nem restritas ao Brasil. A história da introdução de novas doenças ilustra isso 
claramente. Doenças sempre estiveram em movimento: a peste bubônica "invadiu" a Europa vinda da Ásia; varíola, sarampo, febre amarela, malária, cólera e dengue passaram do "Velho Mundo" para o "Novo", enquanto a sífilis avançou na direção oposta. No cômputo final, porém, não resta dúvida de que os nativos americanos levaram a pior, com consequências devastadoras. Estima-se que, entre 1492 e 1595, quase um milhão de pessoas nas Américas morreram de varíola, sarampo, caxumba e outras doenças "europeias". Alguns acreditam que entre $90 \%$ e $95 \%$ da população nativa do Novo Mundo morreram em decorrência de doenças do Velho Mundo. Varíola e sarampo foram os grandes culpados e mataram a maioria dos habitantes autóctones das Américas. Mosquitos e doenças transmitidas por mosquitos tiveram papel particularmente notável, tendo invadido as Américas durante a "Era das Descobertas", quando o imperialismo e o tráfico de escravos a ele associado induziram a circulação de muitas doenças novas ao redor do mundo.

Para que a febre amarela se espalhasse pelas Américas, um novo mosquito, o Aedes aegypti, teve de ser introduzido. A explicação mais provável é que ele foi trazido nas embarcações a vela que transportavam para as Américas africanos escravizados. Esse mosquito encontrou terreno fértil nos centros urbanos em expansão nas Américas, do Brasil aos Estados Unidos. O Aedes aegypti é particularmente bem adaptado ao ambiente urbano, onde há grande concentração de seres humanos e uma infinidade de locais de reprodução. Os mosquitos adultos adaptaram-se aos espaços residenciais e as larvas aquáticas encontraram um lar acolhedor nos recipientes artificiais para água encontrados em quase todas as casas, como caixas d'água, baldes e pneus. $\mathrm{O}$ aumento da população e a crescente densidade das cidades - de acordo com o Banco Mundial, apenas 20\% da população brasileira viviam em cidades em 1900, chegando 30\% em 1940, 55\% em 1970, e a mais de $80 \%$ em 2010 - abriram caminho para a introdução de outros vírus que também são transmitidos por esse mosquito vetor. Mais de um século atrás, chegaram a dengue e seus quatro sorotipos, e a partir de 2013, os vírus chikungunya e zika juntaram-se a eles nas Américas.

O vírus do zika, que é transmitido principalmente pelo Aedes aegypti, foi inicialmente identificado em macacos da floresta Zika, na Uganda, em 1947, e grandes surtos em seres humanos foram relatados pela primeira vez na Micronésia em 2007 e na Polinésia Francesa em 2013. Em 2014, casos de erupção cutânea provocados pelo zika surgiram em vários municípios do Nordeste brasileiro. Em abril de 2015, o vírus já se espalhava por Bahia e Rio Grande do Norte. Em Salvador, quase 15 mil casos similares foram relatados por médicos entre fevereiro e junho de 2015 - a maioria deles associados ao zika. No final de 2015, haviam sido identificados casos em todas as cinco regiões do país e o Ministério da Saúde estimou que entre 500 mil e 1,5 milhão de pessoas haviam sido infectadas. Do Brasil, o vírus migrou para outras partes das Américas, com surtos dignos de nota na América Central, Caribe e partes tropicais da região andina. Embora as 
manifestações clínicas do zika sejam de modo geral consideradas brandas e autolimitativas, o surto de 2015 foi pela primeira vez associado à maior incidência de uma doença neurológica grave, a síndrome de Guillain-Barré. No final de 2015, um aumento de casos de microcefalia em recém-nascidos foi observado no Nordeste e suspeitou-se que as mães haviam sido previamente infectadas com o vírus zika. A atenção mundial voltou-se para esse vírus, que passou a ser visto como uma grande ameaça de saúde pública a mulheres grávidas e seus bebês recém-nascidos. O Ministério da Saúde do Brasil e a Organização Mundial da Saúde (OMS) logo declararam uma emergência de saúde pública.

$\mathrm{O}$ vírus do zika e a reação do governo fazem parte de um contexto maior em que as pessoas mais pobres e as oriundas de classes socioeconômicas mais privilegiadas têm relações cotidianas muito diferentes com o Estado brasileiro. Por exemplo, a esmagadora maioria de assassinatos de cidadãos pela polícia militar ocorre em bairros pobres e é muito mais provável que as vítimas sejam do sexo masculino e de pele mais escura. $\mathrm{Na}$ área da saúde, as políticas eram (e são) criadas por membros de classes dominantes - cientistas, médicos e políticos - cujas abordagens, ainda que muitas vezes bem-intencionadas, podem ser consideradas paternalistas pela população ou mesmo parte de um sistema mais amplo e injusto de controle social.

Tais sentimentos têm uma longa história. No final do século XIX, os membros das classes de elite se recusaram a cumprir as leis de isolamento contra a febre amarela - numa época em que autoridades de saúde pública acreditavam que a doença era contagiosa por contato - se isso implicasse serem alojados no mesmo local que pacientes das classes populares. Visto que o governo não usaria contra os brasileiros privilegiados a mesma força com que obrigava os pobres a cumprirem a lei, construiu-se no terreno do Hospital de Isolamento de São Paulo uma mansão especial de isolamento, completa com telhas vindas da França, escadas de mármore da Itália e quartos especiais para os empregados viverem perto de seus patrões. Desse modo, desafios de saúde pública aparentemente simples - por exemplo, qual a melhor forma de conter os mosquitos e as doenças que eles causam - não podem ser dissociados de incidentes que desde há muito tempo fazem o povo desconfiar do Estado e de seus agentes.

Reações populares negativas a políticas nacionais de saúde ocorrem desde que o Brasil se tornou uma república em 1889, após mais de 75 anos como Império e séculos como colônia de Portugal. Nos primeiros anos do século XX, o presidente Rodrigues Alves instituiu um conjunto de reformas urbanas na capital, na época o Rio de Janeiro, incluindo a demolição de edificações mais antigas e de cortiços. Em seu lugar, moradias mais luxuosas foram erguidas e seguiu-se a expulsão da população pobre da cidade para locais mais distantes - fenômeno que continua até hoje no Brasil e em muitos outros países. Como parte desse plano de governo, a Fundação Oswaldo Cruz (Fiocruz) adquiriu nova importância graças à sua parceria com o que é hoje o Ministério da Saúde. 
Sob a liderança de seu fundador, o médico epidemiologista e sanitarista Oswaldo Cruz, a Fiocruz empreendeu a missão de enfrentar os desafios de saúde pública numa época em que muitos brasileiros cultos acreditavam que os setores mais pobres e de ascendência africana da população eram "naturalmente" mais fracos e mais suscetíveis a doenças do que a elite descendente de europeus. Valendo-se de métodos tidos majoritariamente como "científicos" (por exemplo, frenologia e eugenia), intelectuais, médicos e cientistas concluíram que muitos elementos do povo eram "degenerados" - uma palavra encontrada repetidamente em estudos médicos e de saúde anteriores a 1945 e que continua a ser usada na linguagem cotidiana para referir-se aos pobres.

Em 1904, Oswaldo Cruz recebeu autorização federal para efetuar amplas melhorias sanitárias no Brasil, o que incluiu a criação das "Brigadas Mata-Mosquitos". Começando com esse programa, os agentes sanitários receberam autoridade legal para entrar na casa dos brasileiros e exterminar os mosquitos que transmitiam a febre amarela, bem como os ratos que transmitiam a peste bubônica. Não chega a surpreender que a reação pública às "Brigadas Mata-Mosquitos" tenha sido ambígua. De modo geral, membros da elite acolheram bem um projeto que, a seu ver, resolveria os problemas nacionais da cultura, mão de obra e saúde "degeneradas" decorrentes da escravidão e do número de cidadãos de ascendência africana no país. Os segmentos mais economicamente marginalizados, por outro lado, tendiam a ver os agentes sanitários mais como agentes de controle social dirigidos pelo Estado do que como indivíduos que priorizavam a saúde e o bem-estar da comunidade - especialmente quando realizavam o seu trabalho escoltados por policiais armados. De fato, até meados do século XX, um dos termos oficiais usados para designar essas pessoas era "polícia sanitária".

A frustração com as políticas de saúde implantadas pelo Estado - às vezes bem intencionadas, outras vezes nem tanto - levou, em 1904, à "Revolta da Vacina". Esse levante no Rio de Janeiro, que durou uma semana, seguiu à aprovação pelo Congresso de uma proposta de Cruz instituindo a vacinação obrigatória. Isso conferiu aos agentes de saúde o direito de entrar na casa dos cariocas, acompanhados pela polícia, para aplicar a vacina contra a varíola - à força, se necessário. Houve uma verdadeira guerra civil entre as autoridades e a população, que deixou trinta mortos e centenas de feridos e presos. Considerando-se que uma caracterização muito comum das relações Estado/cidadão no início do século XX era a de que "a questão social é caso de polícia", não chega a surpreender que a reverência com que Oswaldo Cruz e sua fundação são vistos hoje, pelo menos entre a elite do Brasil, não se estendesse a todos os setores da população.

Para muitos estudiosos da cultura brasileira, aspectos dos conflitos sociais que levaram à "Revolta da Vacina" também podem ser encontrados na crise contemporânea envolvendo doenças transmitidas por mosquitos como chikungunya, dengue e, especialmente, as causadas pelo vírus do zika. A maioria da população parece aceitar - até mesmo de bom grado - as medidas de erradicação 
e de controle implementadas pelo Estado, uma vez que as visitas domiciliares regulares por parte dos agentes de controle de vetores podem contribuir para criar relações positivas entre eles e as populações que atendem. No entanto, em fevereiro de 2016, quando o exército brasileiro, com seu slogan "braço forte, mão amiga", foi incumbido de realizar visitas de erradicação do mosquito e de enviar médicos uniformizados para as clínicas de saúde pública que as classes mais ricas não utilizam cotidianamente, outras questões vieram à tona. Alguns comentadores se perguntaram como os moradores se sentiriam diante disso dadas as inúmeras mortes de civis pelas mãos de policiais e militares ocorridas ao longo da "pacificação" de bairros pobres. Outros perguntaram se era possível imaginar alguma circunstância em que soldados fossem enviados a edifícios residenciais em bairros de elite. Houve até relatos de que o alto comando militar não autorizou a entrada de soldados uniformizados em bairros considerados "perigosos demais" - a saber, bairros que os oficiais acreditavam serem controlados por organizações criminosas.

$\mathrm{Na}$ metrópole de São Paulo, como na maioria das grandes cidades, as doenças transmitidas por mosquitos afetam cada bairro de maneiras muito diferentes. Em grande parte, essas variações são uma função da proliferação dos locais de reprodução e das oportunidades de encontro entre mosquitos e seres humanos, que por sua vez dependem da densidade de pessoas e de insetos. A qualidade das moradias, a existência ou não de rede de água e esgoto, a temperatura (por exemplo, o efeito ilha de calor), a exposição prévia ao vírus e outros fatores ajudam a determinar as taxas de transmissão e de infecção. Pressupostos culturais e políticos sobre classe, gênero e raça influenciam tanto as decisões orçamentárias quanto as políticas. Cartazes de advertência com imagens enormes de mosquitos tornaram-se parte integrante da paisagem visual brasileira contemporânea. Embora alguns desses cartazes ofereçam uma visão realista da ameaça, uma grande parte da campanha retrata os mosquitos como monstros com presas, um resquício das imagens do início do século XX usadas pelo governo em folhetos educativos. Profissionais de saúde pública hoje reclamam que essa abordagem pode levar o público a achar que qualquer inseto voador é um perigo iminente, e não o Aedes aegypti especificamente.

Anúncios que retratam os mosquitos como monstros fazem parte de um contexto mais amplo no qual, por três motivos fundamentais, os bairros mais pobres e seus moradores arcam com uma parcela desproporcional da doença. Primeiro, esses espaços tendem a ter concentrações maiores de pessoas vivendo em íntima proximidade umas com as outras. É o que ocorre não só nas comunidades mais pobres, mas também nos bairros operários. Segundo, hoje, como há um século, os formuladores de políticas de saúde e as autoridades encarregadas de implementá-las provêm de setores da sociedade cujas relações com as pessoas de baixa renda tendem a refletir os extremos que caracterizam a sociedade brasileira há décadas. 
Por fim, a concentração da doença em bairros marginalizados está relacionada ao fornecimento irregular e imprevisível de água, uma vez que a pressão das tubulações diminui quanto mais longe se vive dos pontos centrais de distribuição, muitas vezes localizados longe das periferias. Essa situação geral é agravada pela seca, como a que atingiu as cidades de São Paulo e Rio de Janeiro em 2015. Nos bairros menos privilegiados, portanto, cada família tem sua própria caixa d'água para armazenar água de beber, cozinhar e realizar higiene pessoal. São geralmente recipientes redondos de plástico, com cerca de um metro de diâmetro, que são enchidos nos dias em que o bairro recebe água (o que em algumas partes da cidade pode ocorrer apenas duas ou três vezes por semana). Se estiverem em mau estado ou não forem devidamente tampadas, as caixas d'água podem se tornar locais excelentes para a reprodução das larvas do Aedes aegypti. Bairros de classes mais privilegiadas, por outro lado, especialmente aqueles que concentram edifícios de apartamentos, recebem água regularmente e a manutenção dos grandes tanques dos prédios é feita por funcionários do condomínio, não por cada família individualmente.

Essas três questões ficaram evidentes em nosso projeto de pesquisa interdisciplinar, financiado pela Emory University, pelo Instituto de Estudos Avançados da Universidade de São Paulo e pelo governo federal brasileiro, que combina métodos históricos, antropológicos e epidemiológicos para estudar doenças na cidade de São Paulo ao longo de um século. Em março de 2016, acompanhados de agentes da vigilância sanitária, fomos para o bairro do Capão Redondo, distrito de 275 mil habitantes que faz parte da subprefeitura do Campo Limpo - um nome com inevitável conotação irônica. De acordo com o Instituto Brasileiro de Geografia e Estatística, a renda média em Capão Redondo é de cerca de 2,5 salários mínimos, e mais de $50 \%$ da população ganham menos de cinco salários mínimos por mês e outros $30 \%$ têm como única fonte de renda os benefícios concedidos do Estado.

A densidade das moradias residenciais é impressionante no Capão Redondo. A maioria das estruturas abriga entre seis ou oito domicílios, nos quais cada família ocupa dois ou três aposentos. Em outras palavras, habitações que em bairros abastados teriam quartos separados, sala de estar, sala de jantar e uma cozinha, nas regiões mais pobres são comprimidas em espaços muito menores que se prestam a várias funções. Cada família tem seu próprio reservatório de água, que é abastecido pela rede pública de água em dias imprevisíveis, quando a pressão da água é suficiente. Além disso, muitas estruturas habitacionais estão em constante construção ou na esperança de construção. Na prática, isso significa que as edificações raramente têm um telhado acabado, mas sim um piso superior feito com materiais que poderão vir a ser utilizados para a futura criação de novos andares e, portanto, de mais aposentos para mais famílias.

Entramos em inúmeros imóveis junto com os agentes de vigilância sanitária, cujo objetivo é educar o público sobre métodos para controlar os mosquitos 
e encontrar os locais onde eles se reproduzem. Embora muitos problemas sejam fáceis de resolver (por exemplo, virar recipientes com água de cabeça para baixo), outras questões são mais desafiadoras. A coleta de lixo, por exemplo, não é regular em muitos bairros do Brasil e diversos itens - desde sacos plásticos até vasilhames descartados - rapidamente se tornam criadouros potenciais após a chuva. Andares superiores inacabados de moradias muitas vezes acabam entulhados com objetos pesados de grande porte que não podem ser facilmente cobertos ou virados.

As caixas d'água também são uma possível fonte de problemas. Embora muitas famílias tenham caixas relativamente modernas feitas de plástico durável de alto impacto (e, às vezes, de alumínio), muitas outras ainda usam as caixas antigas, com tampas rachadas ou quebradas, criando um local ideal para a reprodução dos mosquitos. Embora longe de ser uma amostragem científica, ao longo de um único dia no Capão Redondo todos os dez imóveis que visitamos tinham pelo menos uma caixa d'água com a tampa quebrada, na qual os agentes sanitários encontraram larvas, constituindo um grave risco para todas as famílias que compartilham a mesma edificação. Como não existe um padrão nacional para caixas d'água no Brasil, alguns erros de projeto na sua fabricação são bastante comuns e também podem criar problemas. Por exemplo, as caixas usam uma boia para interromper o fluxo de água quando estão cheias. Como as boias podem às vezes não funcionar, todas as caixas também têm um orifício - chamado ladrão - para escoar a água excedente. $O$ preço das caixas não inclui um plugue para tapar o ladrão e muitas pessoas não têm condições de adquirir um extravasor mais sofisticado com trava móvel. Em outras palavras, mesmo uma caixa d'água de alta qualidade pode ter uma abertura através da qual os mosquitos entram. Embora esse orifício seja fácil de tapar quando a caixa está dentro da casa, em alguns bairros - especialmente aqueles onde os imóveis estão sempre sendo ampliados informalmente para cima - as caixas acabam sendo montadas no alto do telhado e não são facilmente acessíveis.

Os agentes de vigilância sanitária que acompanhamos aconselharam os moradores cujas caixas tinham a tampa quebrada que as substituíssem ou que vedassem a saída com algum tipo de adesivo epóxi. Também buscaram soluções criativas para o problema, como sugerir que sacos plásticos velhos fossem usados para tapar buracos. Contudo, quando a tampa está rachada e a única solução é substituí-la, as famílias nem sempre têm dinheiro para comprar uma nova, ou não dispõem de um veículo que possa levar a tampa recém-adquirida da loja para a casa. Em um caso, um agente sanitário ofereceu-se para procurar uma tampa substituta no depósito de seu departamento se a família encontrasse uma maneira de ir pegá-la no seu local de trabalho.

Quando larvas eram encontradas numa caixa d'água, os agentes de vigilância sanitária orientavam os moradores sobre como limpar a superfície interna com uma solução química. No entanto, o abastecimento irregular de água torna 
difícil seguir essa prescrição. Quando perguntamos a um dos agentes por que a cidade não fornecia tampas ou se responsabilizava pela limpeza das caixas (a cidade de São Paulo já teve um programa que fornecia tampas ou uma lona que passava por cima da caixa e abaixo da tampa quebrada), a resposta foi que era importante que a população aprendesse que a saúde é uma responsabilidade sua. $\mathrm{O}$ agente admitiu que essa abordagem não está dando muito certo; no Brasil, como em outros países, uma das prioridades tem sido acabar com a grande contribuição das caixas d'água para a proliferação de mosquitos.

Por fim, os agentes sanitários enfrentam diversas complicações sempre presentes. Uma das mais graves é o temor dos moradores de terem sua casa invadida. A fim de conseguir que os moradores autorizem a inspeção de suas moradias, os agentes de vigilância sanitária pedem-lhes que confirmem para os vizinhos quem eles são ou que liguem para a prefeitura para conferir o número de identificação do agente. Em muitos casos, isso é suficiente. Os agentes que acompanhamos tinham o direito legal de insistir para entrar, mas disseram-nos que não iriam forçar por uma questão de segurança pessoal. $\mathrm{O}$ endereço dos moradores que se recusam a abrir sua casa é cuidadosamente anotado e as informações são encaminhadas para providências futuras. Pesquisadores certamente acharão esse material fascinante quando se tornar disponível.

O surgimento do vírus do zika foi acompanhado de consequências trágicas, especialmente para as mulheres. No final de março de 2016, as autoridades brasileiras haviam confirmado 907 casos de microcefalia e 198 bebês com esse defeito de nascença já morreram desde que o surto começou. No momento em que escrevemos este artigo, a Organização Mundial de Saúde prevê que em breve o número total de casos de microcefalia no Brasil ultrapassará 2,5 mil. Ou seja, a situação atual levou as questões práticas e éticas a um ponto crítico. Esses desafios refletem a persistência e a geografia social da desigualdade no Brasil; os menos favorecidos não só são mais suscetíveis a serem expostos ao vírus como também contam com menos alternativas de tratamento, tendo diante de si uma gama limitada de opções de saúde reprodutiva e precisando suportar o fardo de custos econômicos de longo prazo para si e suas famílias.

RESUMO - A crise do vírus do zika, como todas as doenças, é um indicador da desigualdade que persiste no Brasil mesmo após décadas de democracia. O zika ilustra disparidade não apenas em termos de classe e com a variedade de questões que se conectam com classe, como gênero e raça. Questões éticas relacionadas ao vírus do zika também têm impactos diferenciais em termos de escolhas reprodutivas, no uso de produtos químicos para a pulverização e no desenvolvimento de mosquitos geneticamente modificados. Ao utilizarem um conjunto multidisciplinar de métodos baseados em história, antropologia e ecoepidemiologia, os autores mostram como a crise atual do zika é parte do histórico de saúde no Brasil com as relações muitas vezes tensas entre atores estatais e população em geral. 
PALAVRAS-CHAVE: Epidemiologia histórica, Zika, Desigualdade social, Saúde pública, Brasil.

ABSTRACT - The Zika virus crisis, like of all diseases, is an indicator of the inequality that persists in Brazil, even after decades of democracy. Zika illustrates disparity not only in terms of class, and a variety of other issues linked to class, but also of gender and race. Ethical issues related to the Zika virus also have different impacts in terms of reproductive choices, the use of chemicals for spraying, and the development of genetically-modified mosquitoes. By using a multi-disciplinary set of methods based on history, anthropology, and eco-epidemiology, the authors show how the current Zika crisis is part of the long history of health in Brazil, with often-tense relations between agents of the State and the population at-large.

KErWORDS: Historical epidemiology, Zika, Social inequality, Public health, Brazil.

Jeffrey Lesser é professor de Estudos Brasileiros (cátedra Samuel Candler Dobbs) e chefe do Departamento de História da Emory University, Atlanta, Georgia, Estados Unidos. Professor visitante no Instituto de Estudos Avançados da Universidade de São Paulo. Seu livro mais recente é $A$ invenção da brasilidade: identidade nacional, etnicidade e políticas de imigração (Editora Unesp, 2015). @ - <jlesser@emory.edu>

Uriel Kitron é mestre e doutor em Saúde Pública, professor (cátedra Goodrich C. White) e chefe do Departamento de Ciências Ambientais da Emory University, Atlanta, Georgia, Estados Unidos. @ - ukitron@emory.edu

Tradução de Carlos Malferrari. O original em inglês - "The social geography of zika in Brazil" - encontra-se à disposição do leitor no IEA-USP para eventual consulta. Uma versão do artigo foi publicada como "The social geography of zika in Brazil", NaclaReport on the Americas, v.48, n.2, p.123-9, Summer, 2016.

Recebido em 4.8.2016 e aceito em 20.9.2016.

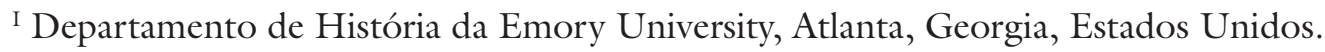

II Departamento de Ciências Ambientais da Emory University, Atlanta, Georgia, Estados Unidos. 